
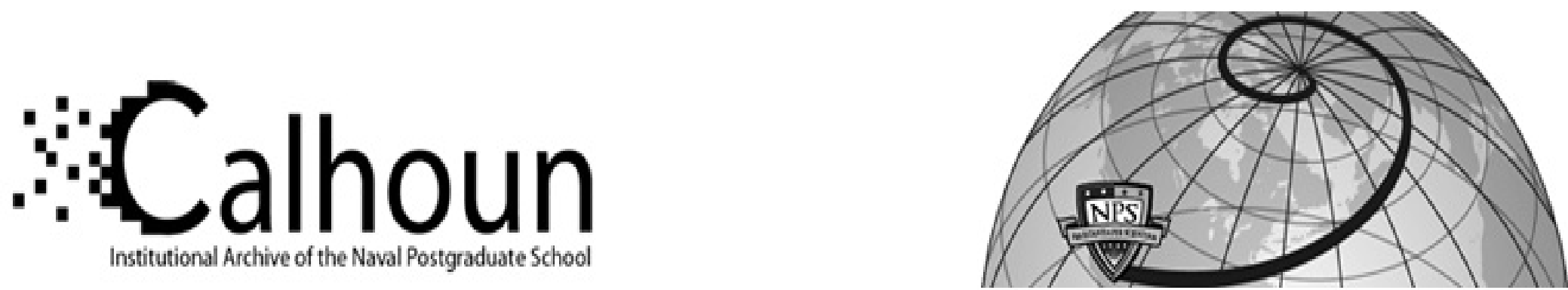

Calhoun: The NPS Institutional Archive DSpace Repository

\title{
Yellow Sea Acoustic Uncertainty caused by hydrographic data error
}

Schneider, D.; Keenan, R.E.; Fox, D.N.; Chu, Peter C.; Cintron, C.J.; Haeger, S.D.

Chu, P.C., C. J. Cintron, S. D. Haeger, D. Schneider, R. E. Keenan, D.N. Fox, 2002: Yellow Sea Acoustic Uncertainty caused by hydrographic data error. International Conference on Impact of Littoral Environmental Variability on Acoustic Predictions and Sonar Performance, 563-570

https://hdl.handle.net/10945/36276

This publication is a work of the U.S. Government as defined in Title 17, United States Code, Section 101. Copyright protection is not available for this work in the United States.

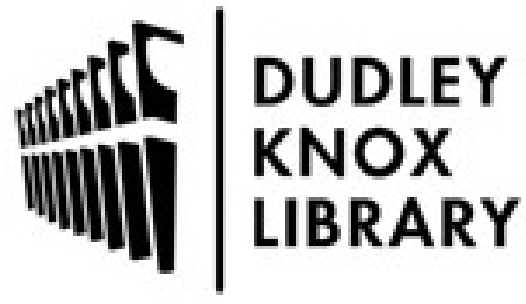

http://www.nps.edu/library
Calhoun is the Naval Postgraduate School's public access digital repository for research materials and institutional publications created by the NPS community. Calhoun is named for Professor of Mathematics Guy K. Calhoun, NPS's first appointed -- and published -- scholarly author.

Dudley Knox Library / Naval Postgraduate School 411 Dyer Road / 1 University Circle Monterey, California USA 93943 


\title{
YELLOW SEA ACOUSTIC UNCERTAINTY CAUSED BY HYDROGRAPHIC DATA ERROR
}

\author{
PETER C. CHU AND CARLOS J. CINTRON \\ Naval Postgraduate School, 833 Dyer Road, Monterey CA 93943, USA \\ E-mail:chu@nps.navy.mil \\ STEVEN D. HAEGER, AND DAVID SCHNEIDER \\ Naval Oceanographic Office, Stennis Space Center, MS 39529, USA \\ E-mail:haegers@navo.navy.mil \\ RUTH E. KEENAN \\ Scientific Application International Corporation, Mashpee, MA02649, USA \\ E-mail: rkeenan@capcod.net \\ DANIEL N. FOX \\ Naval Research Laboratory, Stennis Space Center, MS 39529, USA \\ Email:fox@nrlssc.navy.mil
}

\begin{abstract}
This paper investigates the acoustic uncertainty due to hydrographic data error and in turn to determine the necessity of a near real time ocean analysis capability such as the Naval Oceanographic Office's (NAVOCEANO) Modular Ocean Data Assimilation System (MODAS) model in shallow water (such as the Yellow Sea) mine hunting applications using the Navy's Comprehensive Acoustic Simulation System/Gaussian Ray Bundle (CASS/GRAB) model. To simulate hydrographic data uncertainty, Gausian-type errors (produced using the random number generator in MATLAB) with zero mean and three standard deviations $(1 \mathrm{~m} / \mathrm{s}, 5 \mathrm{~m} / \mathrm{s}$, and $10 \mathrm{~m} / \mathrm{s})$ are added to the sound profile. It is found that the acoustic uncertainty depends on the location of the error and sound sources. It is more sensitive to errors in the isothermal structure in the winter than in the layered structure in the summer.
\end{abstract}

\section{Introduction}

The major threats in the littoral are diesel submarines and sea mines. The combination of improvements in noise reducing technology and the development of Air Independent Propulsion (AIP) technology have made diesel submarines very difficult to detect in both the littoral and blue waters. After a weapon platform has detected its targets, the sensors on torpedoes designed for blue water operations are not designed to acquire a target in a reverberation-crippling environment. Recently, the U.S. Navy has focused much of its research and development efforts in designing high frequency sensors and corresponding acoustic models to overcome the threat in the littoral. The Comprehensive Acoustic Simulation System (CASS) 


\section{P.C. CHU ET AL.}

using the Gaussian Ray Bundle (GRAB) model is a valuable tool for the AN/SQQ-32 mine hunting detection and classification sonar. The performance of this model, as in all models, is determined by the accuracy of its inputs such as sea surface conditions, bathymetry, bottom type, and sound speed profiles. Here, the effect of sound speed errors (i.e., hydrographic errors) on the acoustic uncertainty in the Yellow Sea is investigated using CASS/GRAB.

\section{Environment of the Yellow Sea}

\subsection{Geology and Structure}

The Yellow Sea is a semi-enclosed basin situated between China and the Korean peninsula with the Bohai Sea to the northwest and the East China Sea to the south. The Yellow Sea is a large shallow water basin covering an area of approximately 295,000 $\mathrm{km}^{2}$. The water depth over most of the area is less than $50 \mathrm{~m}$ (Fig. 1). The bottom sediment of the central and western regions of the Yellow Sea consists primarily of mud and the eastern region is primarily sand. The mud sedimentation in the central and northwestern regions of the Yellow Sea is due to the runoff from the great rivers of China. Four regions with different bottom types were selected for the acoustic model runs in this study (Fig. 2): (a) rock bottom type which is located in the north-central Yellow Sea at $37^{\circ}-37.5^{\circ} \mathrm{N}, 123^{\circ}-123.8^{\circ} \mathrm{E}$, (b) gravel bottom type which is located in the northern Yellow Sea at $38.4^{\circ}-39^{\circ} \mathrm{N}, 122^{\circ}-123^{\circ} \mathrm{E}$, (c) sand bottom type which is located in the southeastern Yellow Sea at $35.5^{\circ}-36.5^{\circ} \mathrm{N}, 124.5^{\circ}-126.2^{\circ} \mathrm{E}$, and (d) mud bottom type which is located in the south-central Yellow Sea at $35^{\circ}-36.5^{\circ} \mathrm{N}, 123^{\circ}-124.5^{\circ} \mathrm{E}$.

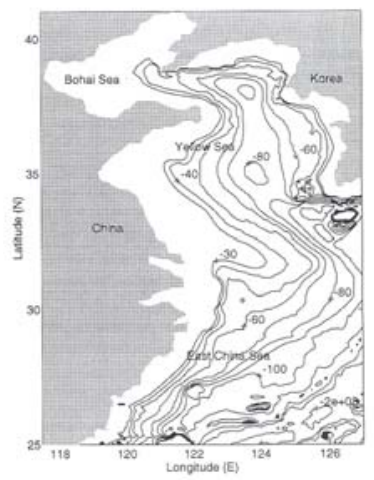

Fig. 1. Bottom Topography of the Yellow Sea and the surrounding regions chart

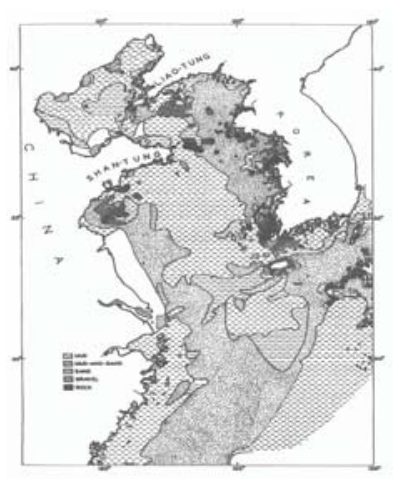

Fig. 2. Yellow Sea Bottom sediment

\subsection{Oceanography}

The four seasons in the Yellow Sea are defined as follows: the winter months run from January through March; the spring months run from April through June; the summer months run from July through September; and the fall months run from October through 
December. The two main characteristic temperature profiles of the Yellow Sea are during the winter and the summer months. In the winter months, the temperature profiles throughout the region are characterized as isothermal (Fig. 3a). In the summer months, the temperature profiles throughout the region are characterized by a multi-layer profile consisting of a mixed layer, a thermocline, and a deep layer (Fig. 3b).

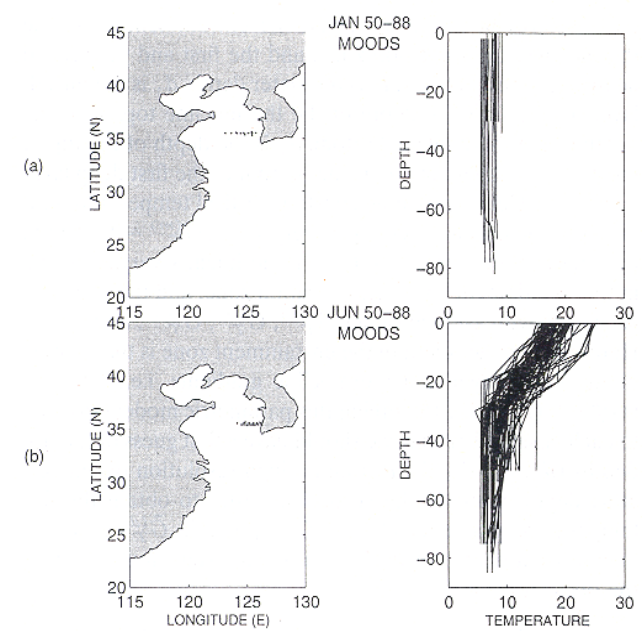

Fig. 3. Eastern Yellow Sea (around $36 \mathrm{~N}$ ) temperature profiles during 1950-1988; (a) January and (b) June. Solid dots show the location of the observation stations (From Chu et al. 1997b).

\section{CASS/GRAB Model}

CASS/GRAB is an active and passive range dependent propagation, reverberation, and signal excess acoustic model and is accepted as the Navy's standard model. The GRAB model's main function is to calculate eigenrays in range-dependent environments in the frequency band $600 \mathrm{~Hz}$ to $100 \mathrm{kHz}$ and to use the eigenrays to calculate propagation loss. The CASS model is the range dependent improvement of the Generic Sonar model (GSM). CASS performs range independent monostatic and bistatic active signal excess calculations. The major difference between the GRAB model and a classic ray path is that the amplitude of the Gaussian ray bundles is global, affecting all depths to some degree, whereas classic ray path amplitudes are local. GRAB calculates amplitude globally by distributing the amplitudes according to the Gaussian equation

$$
\begin{gathered}
\Psi_{v}=\frac{\beta_{v, 0} \Gamma_{v}{ }^{2}}{\sqrt{2 \pi} \sigma_{v} p_{r, v} r} \exp \left\{-0.5\left[\left(z-z_{v}\right) / \sigma_{v}\right]^{2}\right\}, \\
\sigma_{v}=(0.5)(\max (\Delta z, 4 \pi \lambda)),
\end{gathered}
$$

where the $\Gamma_{v}$ represents losses due to volume attenuation and boundary interaction; $\sigma_{v}$ is the effective standard deviation of the Gaussian width; and $\beta_{v, 0}$ is a factor that depends only on the source and is chosen so that the energy within a geometric-acoustic ray tube equals the energy within a Gaussian ray bundle. The variable $z_{v}$ is the depth along the $v^{\text {th }}$ test ray at range $r, z$ is the target depth, $p_{\mathrm{r}}$ is the horizontal slowness, $\Delta z$ is the change in ray depth at constant range due to a change in source angle, and $\lambda$ is the 


\section{P.C. CHU ET AL.}

wavelength. The selection of the effective standard deviation $\sigma_{v}$ is the weakest component in providing a firm theoretical basis for the GRAB model. GRAB computes the random or coherent propagation loss from the eigenrays stored in the eigenray file and stores in them in separate pressure files (Aidala et al. 1998).

\section{Modular Ocean Data Assimilation System}

Modular Ocean Data Assimilation System (MODAS), recently developed at the Naval Research Laboratory (NRL), uses a modular approach to generate three-dimensional gridded fields of temperature and salinity. Its data assimilation capabilities may be applied to a wide range of input data, including randomly located in-situ, satellite, and climatological data. Available measurements from any or all of these sources are incorporated into a three-dimensional, smoothly gridded output field of temperature and salinity. MODAS' primary outputs are temperature and salinity fields that may be used to calculate three-dimensional sound speed fields. The sound speed field, in turn, may be used to drive acoustic performance prediction scenarios, including simulations, tactical decision aids, and other capabilities. These are employed in a wide variety of naval applications and tactical decision aids (TDAs) (Fox et al. 2002).

\section{Acoustic Characteristics}

On February 15,2000 , the sound speed profile at $36.4^{\circ} \mathrm{N}, 124.4^{\circ} \mathrm{E}$ (mud bottom) from MODAS is quite uniform. The sound speed decreases $0.2 \mathrm{~m} / \mathrm{s}$ from the surface to $8.2 \mathrm{ft}$ depth, increases $0.1 \mathrm{~m} / \mathrm{s}$ from $8.2 \mathrm{ft}$ to $41.0 \mathrm{ft}$ depth, and $0.2 \mathrm{~m} / \mathrm{s}$ from $41.0 \mathrm{ft}$ to $57.4 \mathrm{ft}$ depth. The weak sound speed minimum at near surface ( $8.2 \mathrm{ft}$ depth) generates a weak sound channel with sound source at $25 \mathrm{ft}$ (Figure 4) and $125 \mathrm{ft}$ (Figure 5).

Table 1. Sound speed from MODAS on February 15,2000 , at $36.4^{\circ} \mathrm{N}, 124.4^{\circ} \mathrm{E}$, mud bottom

\begin{tabular}{|c|c|}
\hline \multicolumn{2}{|c|}{ mud bottom } \\
\hline Depth (Feet) & M/S \\
\hline 0.00 & 1479.90 \\
8.20 & 1479.70 \\
24.60 & 1479.80 \\
41.00 & 1479.80 \\
57.40 & 1480.00 \\
82.00 & 1480.00 \\
106.60 & 1480.10 \\
131.20 & 1480.30 \\
164.00 & 1480.50 \\
205.00 & 1480.40 \\
246.00 & 1480.40 \\
\hline
\end{tabular}

\section{Acoustic Uncertainties}

To simulate hydrographic data uncertainty, a Gausian-type error (produced using the random number generator in MATLAB) with zero mean and three standard deviations $(1 \mathrm{~m} / \mathrm{s}, 5 \mathrm{~m} / \mathrm{s}$, and $10 \mathrm{~m} / \mathrm{s})$ is added to the MODAS sound profiles. All the sound speed profiles with the mud bottom are selected. Two sets of hydrographic data (MODAS and 
MODAS with error) are inputted into the CASS/GRAB model. The model was integrated with two sound source depths (25 and $125 \mathrm{ft}$ ) and two seasons (February 15, 2000 and August 15,2000) to capture the effect of the hydrographic error on the acoustic uncertainty in the Yellow Sea.

Histograms of the detection range difference (acoustic uncertainty) between control (no error) and sensitivity (with error) runs demonstrate that the acoustic uncertainty has non-Gaussian-type distribution in winter (Figure 6) and Gaussian-type distribution in summer (Figure 7) and is much larger in winter than in summer. This indicates that the isothermal structure of the winter profiles is much more susceptible to errors in sound speed. The acoustic uncertainty depends on where the random error is situated in the water column in relation to the position of the source. For a specific profile, if an error of $1 \mathrm{~m} / \mathrm{s}$ is positioned within approximately 5 feet of the source depth and an error of 10 $\mathrm{m} / \mathrm{s}$ is positioned greater than the 5 feet of the source depth, the $1 \mathrm{~m} / \mathrm{s}$ error will have a much greater effect on the acoustic transmission. If the error near the source is positive, the gradient that is formed in the sound speed profile will decrease detection ranges. If the error is negative, the gradient that is formed in the sound speed profile will increase detection ranges.
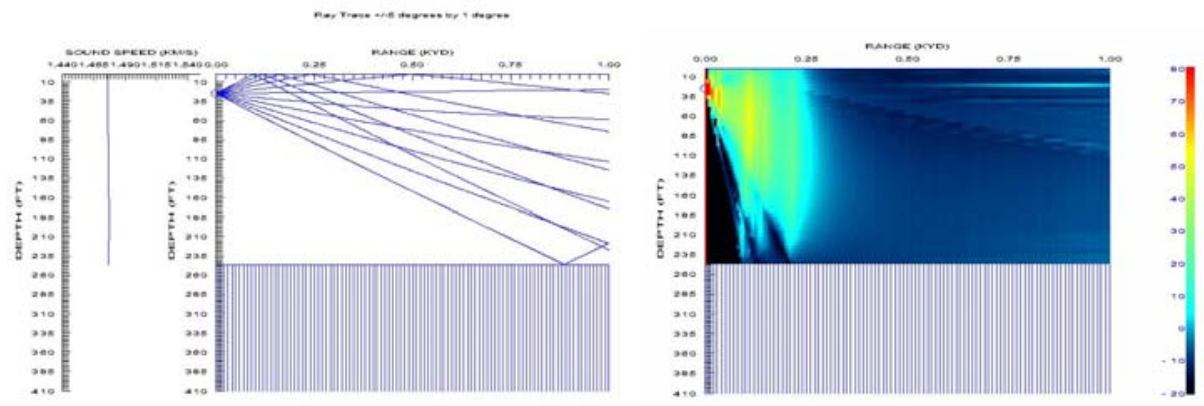

Figure 4. Acoustic transmission with source depth of $25 \mathrm{ft}$ on February 15, 2000 at $36.4 \mathrm{~N} 124.4 \mathrm{E}$ (mud bottom) using the MODAS data: (a) ray trace, and (b) signal excess. Notice that a maximum detection range is $260 \mathrm{yd}$ near the sound source.
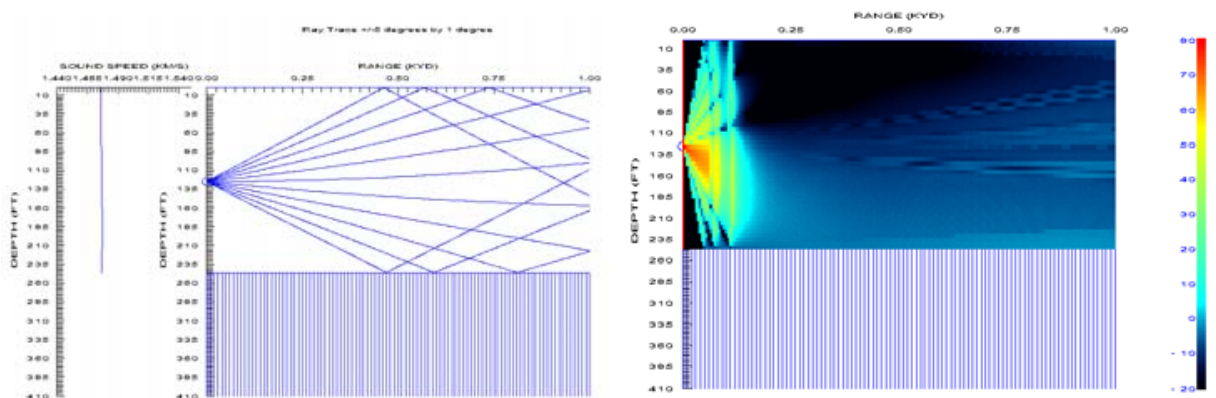

Figure 5. Acoustic transmission with source depth of $125 \mathrm{ft}$ on February 15, 2000 at 36.4 N $124.4 \mathrm{E}$ (mud bottom) using the MODAS data: (a) ray trace, and (b) signal excess. Notice that a maximum detection range is $145 \mathrm{yd}$ near the sound source. 

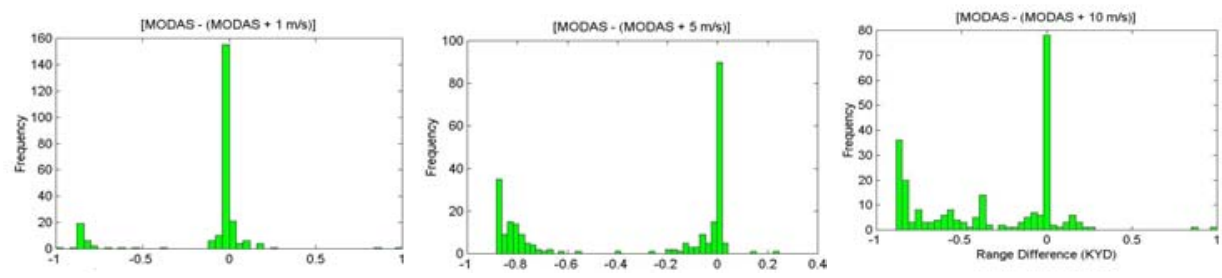

Figure 6. Histograms of the detection range difference caused by the Gaussion-type errors in the sound speed profiles on February 15, 2000 with the mud bottom and $125 \mathrm{ft}$ source depth: (a) MODAS minus MODAS with $1 \mathrm{~m} / \mathrm{s}$ error, (b) MODAS minus MODAS with $5 \mathrm{~m} / \mathrm{s}$ error, and (c) MODAS minus MODAS with $10 \mathrm{~m} / \mathrm{s}$ error.
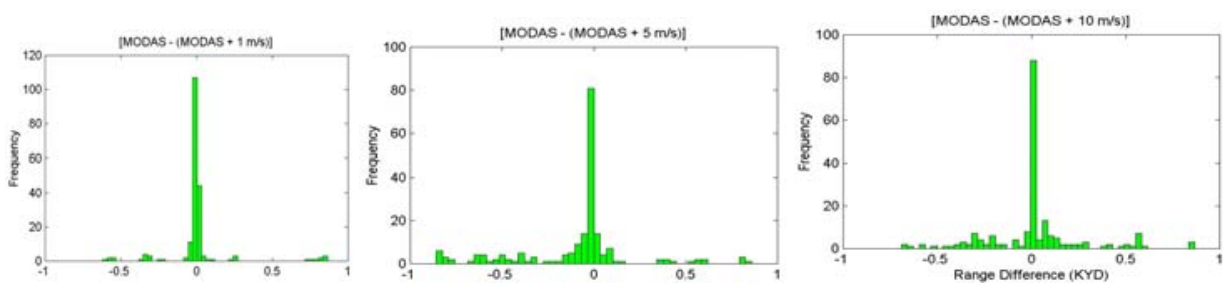

Figure 7. Histograms of the detection range difference caused by the Gaussion-type errors in the sound speed profiles on August 15, 2000 with the mud bottom and $125 \mathrm{ft}$ source depth: (a) MODAS minus MODAS with $1 \mathrm{~m} / \mathrm{s}$ error, (b) MODAS minus MODAS with $5 \mathrm{~m} / \mathrm{s}$ error, and (c) MODAS minus MODAS with $10 \mathrm{~m} / \mathrm{s}$ error.

\section{Hydrographic Errors at the Source Depth}

When an error $(+1 \mathrm{~m} / \mathrm{s})$ was added into the MODAS sound speed profile at both source depths (25 and $125 \mathrm{ft}$ ), a shadow zone was formed in front of the source that significantly decreased the detection ranges at that depth (Figures 8 and 9). When an error $(-1 \mathrm{~m} / \mathrm{s})$ was added into the MODAS sound speed profile at both source depths, a strong sound channel formed that dramatically increased detection ranges at that depth (Figures 10-11).
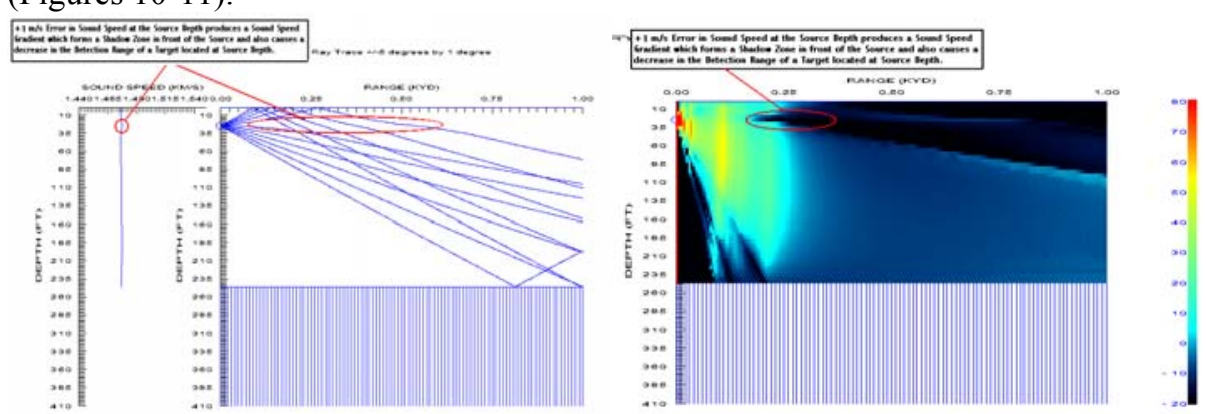

Figure 8. MODAS with $+1 \mathrm{~m} / \mathrm{s}$ sound speed error at the source depth $(25 \mathrm{ft})$ on February 15, 2000, 36.4 N 124.4 E, mud bottom: (a) ray trace, (b) signal excess (maximum detection range at source depth $=175$ yd, $\square$ max detection range at the source depth $=-85 \mathrm{yd})$. 

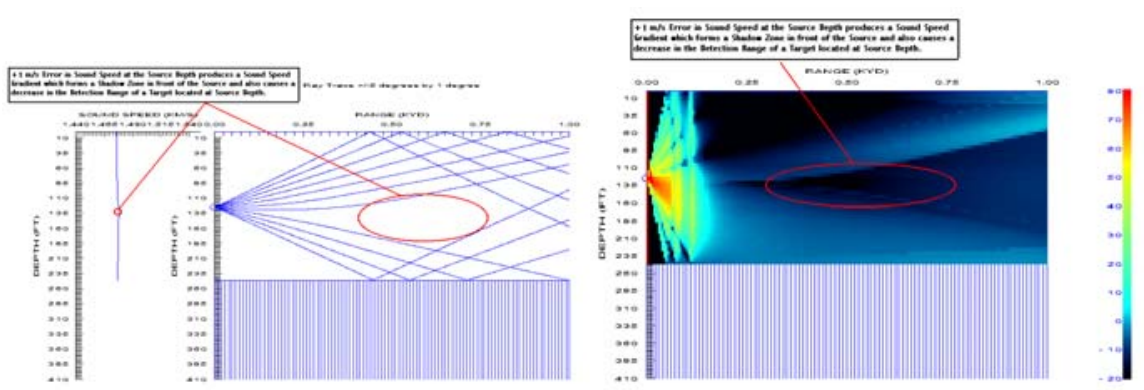

Figure 9. MODAS with $+1 \mathrm{~m} / \mathrm{s}$ sound speed error at source depth $(125 \mathrm{ft})$ on February 15, 2000, 36.4 N 124.4 E, mud bottom: (a) ray trace, and (b) signal excess (maximum detection range near the source depth $=150 \mathrm{yd}$, $\square$ max detection range near the source depth $=-5 \mathrm{yd}$ ).
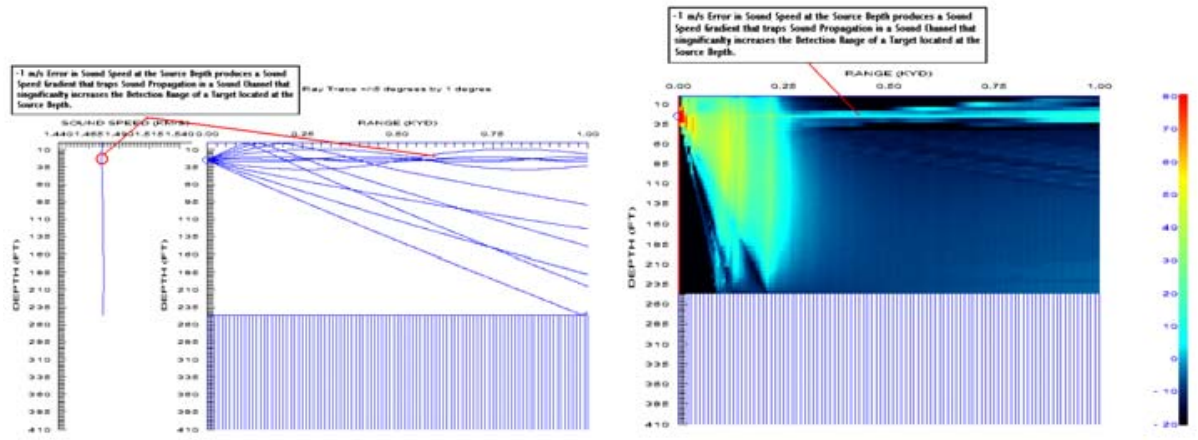

Figure 10. MODAS with $-1 \mathrm{~m} / \mathrm{s}$ sound speed error at the source depth (25 $\mathrm{ft}$ ) on February 15, 2000, 36.4 N 124.4 E, mud bottom: (a) ray trace, and (b) signal excess (maximum detection range near the source depth $>1000 \mathrm{yd}$, $\square$ max detection range near the source depth $>740 \mathrm{yd}$ ).
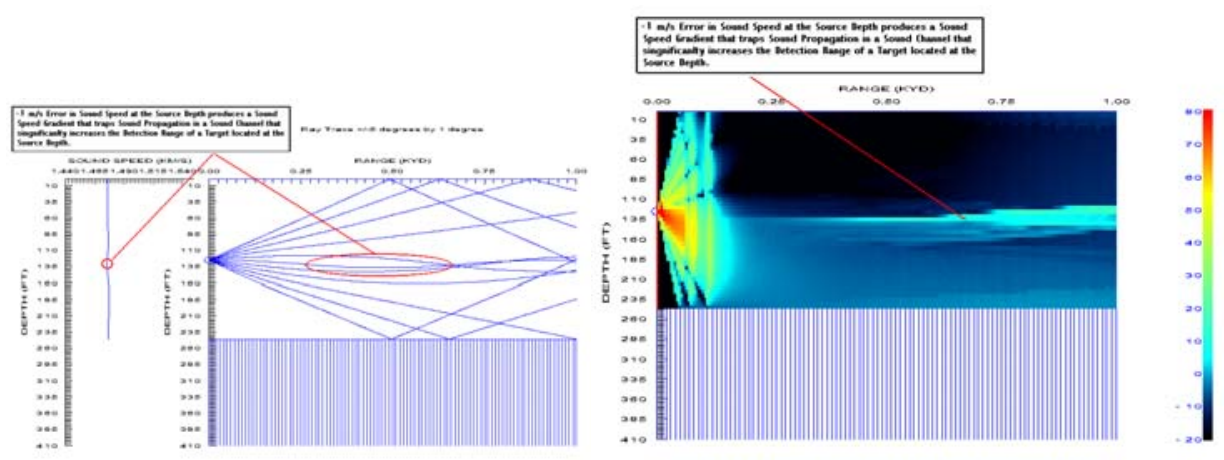

Figure 11. MODAS with $-1 \mathrm{~m} / \mathrm{s}$ sound speed error at the source depth (125 ft) on February 15, 2000, 36.4 N 124.4 E, mud bottom: (a) ray trace, and (b) signal excess (maximum detection range near the source depth $>1000 \mathrm{yd}$, $\square$ max detection range near the source depth $>855 \mathrm{yd}$ ).

\section{Conclusions}

(1) The seasonal variation in acoustic transmission in the Yellow Sea for all regions was mainly due to the isothermal structure in the winter and a multi-layer thermal structure in the summer. The acoustic transmission in the winter is shorter due to the effect of the isothermal structure of the sound speed profile. The acoustic transmission in the 


\section{P.C. CHU ET AL.}

summer is significantly longer due to the down bending effects of the multi-layer structure of the sound speed profiles, which produce convergence zone and caustics.

(2) The acoustic uncertainty due to error in sound speed profiles depends on location of that error relative to the sound source. It has non-Gaussian-type distribution in winter and Gaussian-type distribution in summer and is much larger in winter than in summer.

(3) In winter, when an error $(+1 \mathrm{~m} / \mathrm{s})$ was added into the sound speed profile at the source depth, a shadow zone was formed in front of the source that significantly decreased the detection ranges at that depth. When an error $(-1 \mathrm{~m} / \mathrm{s})$ was added into the sound speed profile at the source depth, a strong sound channel formed that dramatically increased detection ranges at that depth.

\section{Acknowledgements}

This work was supported by the Naval Oceanographic Office and the Naval Postgraduate School.

\section{References}

Aidala, F.E., Keenan, R.E., and Weinberg, H., Modeling high frequency system performing in shallowwater range-dependent environments with the comprehensive acoustic simulation system (CASS). $N U W C$ Division Newport Technical Digest, 54-61 (1998).

Chu, P. C., Wells, S. K., Haeger, S. D., Szczechowski, C., and Carron, M. J., Temporal and Spatial Scales of the Yellow Sea Thermal Variability. J. Geophys. Res., 102, 5657-5658 (1997a).

Chu, P. C., Fralick, C. R., Haeger, S. D., and Carron, M. J, A Parametric Model for the Yellow Sea Thermal Variability. J. Geophys. Res., 102, 10499-10507 (1997b).

Fox, D. N., Teague, W. J., Barron, C.N., Carnes, M.R., and Lee, C.M., The Modular Ocean Data Assimilation System (MODAS). J. Atmos. Oceanic Tech. 19, 240-252 (2002).

Keenan, R., Weinberg, H., E., and Aidala, F. E., Software Requirements Specifications for the Gaussian Ray Bundle (GRAB) Eigenray Propagation Model. OAML-SRS-74, Systems Integration Division, Stennis Space Center, MS (1999).

Keenan, R. E., An Introduction to GRAB Eigenrays and CASS Reverberation and Signal Excess. Science Applications International Corporation, MA (2000).

Naval Oceanographic Office Systems Integration Division, Software Design Document for the Gaussian Ray Bundle (GRAB) Eigenray Propagation Model. OAML-SDD-74. Stennis Space Center, MS (1999)

Naval Oceanographic Office Systems Integration Division, Data Base Description for the Generalized Digital Environmental Model (GDEM-V) Version 2.5. OAML-DBD-72C, Stennis Space Center, MS (2000).

Naval Research Laboratory, User's Manual for the Modular Ocean Data Assimilation System (MODAS) Version 2.1. PSI Technical Report S-285, Stennis Space Center, MS (1999).

Naval Research Laboratory, Confidence Level Assessment of MODAS Appendix 1: Upgraded Altimetry Processing, Stennis Space Center, MS (2000). 